\title{
Role of Hepatic Venous Pressure Gradient as a predictor of response to Endoscopic Variceal Ligation in patients of Cirrhosis with Esophageal varices
}

Authors

\section{Gul Javid*, Ghulam Mohd Gulzar*, Shoib Mohd Patto*, Mohd Sultan Alie $\dagger$, Showkat Ali Zargar*}

*Department of Gastroenterology, Sher-i-Kashmir Institute of Medical Sciences (SKIMS),

Srinagar, J\&K, India 190011

$†$ Department of Cardiology, Sher-i-Kashmir Institute of Medical Sciences (SKIMS),

Srinagar, J\&K, India 190011

Corresponding Author

Dr Gul Javid

Professor, Department of Gastroenterology, Sher-I-Kashmir Institute of Medical Sciences, J\&K, Srinagar

(India) 190011.

Email: guljavid@rediffmail.com, Mobile: 941905793

\begin{abstract}
:-
Background: Portal hypertension is a major consequence of cirrhosis characterized by life threatening variceal bleeding. Estimation of Hepatic venous pressure gradient (HVPG) is the gold standard for diagnosing portal hypertension. Advances in endoscopic treatment have improved survival rates.

Objective: Assessment of HVPG as a predictor of response to endoscopic variceal ligation (EVL) in patients of cirrhosis with esophageal varices.

Material and Methods: HVPG was measured in 40 consecutive cirrhotic patients, 26 had history of variceal bleeding, 27 were males and mean age was $51.05 \pm 9.99$ years. All patients received EVL until variceal eradication.

Results: Ten patients had HVPG $\leq 12 \mathrm{mmHg}, 11$ patients had $13-15 \mathrm{mmHg}, 10$ patients had 16-18 mmHg and 9 patients had $>18 \mathrm{mmHg}$. Mean number of EVL sessions required for variceal eradication in patients with $H V P G \leq 12,13-15,16-18$ and $>18 \mathrm{mmHg}$ were 2.10, 2.64, 4.10, 5.33 respectively. A significantly positive correlation was found between the levels of HVPG and number of EVL sessions required for variceal eradication (correlation coefficient of 0.844, regression coefficient of 0.344). Patients requiring more number of EVL sessions had significantly ( $p<0.001)$ higher mean HVPG levels ascompared to patients requiring less number of EVL sessions. Post hoc analysis on pair wise comparison shows that as HVPG rises, there is significant increase $(p<0.001)$ in number of EVL sessions required for variceal eradication.

Conclusion: HVPG has a significant influence on response to EVL, in terms of number of sessions required for variceal eradication.

Key Words: Cirrhosis, portal hypertension, HVPG, Varices, EVL, Variceal obliteration.
\end{abstract}




\section{Introduction}

HVPG is an indirect measurement of portal hypertension because wedged hepatic venous pressure is very close to portal venous pressure (PVP) in chronic liver diseases, particularly of alcoholic and hepatitis $\mathrm{B}$ and hepatitis C etiology $y^{(1,2,3)}$. The first important step in demonstrating usefulness of HVPG is the threshold value of $12 \mathrm{mmHg}$, above which serious complications of portal hypertension can arise particularly bleeding from gastro- esophageal varices ${ }^{(4,5,6)}$

HVPG is significantly correlated with the ChildTurcotte-Pugh (CTP) and Model for End-Stage Liver Disease (MELD) scores ${ }^{(7,8,9)}$. An HVPG of $\geq 10 \mathrm{mmHg}$ leads to varices and a value $\geq 12$ $\mathrm{mmHg}$ leads to variceal bleeding ${ }^{(10,}{ }^{11)}$. Wadhawan $\mathrm{M}^{(7)}$ in his study concluded that there is a good correlation between HVPG and large varices, bleeding status, and ascites; higher HVPG reflects more severe liver disease and the etiology of liver disease did not influence the portal pressure. HVPG greater than $16 \mathrm{mmHg}$ is an important predictor of poor outcome. ${ }^{(12)}$. In our earlier study we found a significant correlation between HVPG and variceal size, Child-Pugh class, and presence of ascites ${ }^{(13)}$. HVPG measurement is useful in clinical practice while selecting cirrhotic patients at higher risk of variceal bleeding and guiding to specific therapy (14). HVPG measurement also allows the identification of responders and non responders to beta blockers, which explains why protection from gastro- esophageal variceal bleeding is not seen in all treated patients ${ }^{(15,16)}$. Now, it is generally accepted that decreasing the HVPG below a threshold value of $12 \mathrm{mmHg}$ by any drug or combination of drugs almost completely reduces the risk of first or recurrent bleeding from varices. Unfortunately, with currently available drugs, this threshold is not frequently attained, except in patients with mild to moderately elevated HVPG $^{.(17,18)}$ There are many clinical applications of HVPG in predicting liver fibrosis, outcome of acute bleeding, effectiveness of beta blocker prophylaxis and post-operative outcome in hepatocellular carcinoma ${ }^{(19)}$.

In the present study, our primary aim was to assess the role of HVPG as a predictor of response to EVL in patients of cirrhosis (irrespective of etiology) with esophageal varices. So far, no study has been conducted to assess the effect of HVPG on eradication of esophageal varices by EVL.

\section{Materials}

The study was conducted in the department of Gastroenterology SKIMS Soura from June 2012June 2014. Diagnosis of cirrhosis was made on the basis of unequivocal clinical, biochemical and imaging (Computed tomography/ultrasonography findings and biopsy if indicated). All patients had an upper GI endoscopy to assess the presence and grade of esophageal varices.

\section{Inclusion Criteria}

Patients of established cirrhosis of liver irrespective of etiology and endoscopically proven medium/large esophageal varices with or without variceal bleeding.

\section{Exclusion Criteria}

Patients with encephalopathy, patients with spontaneous bacterial peritonitis, active variceal bleeding, patients with hepatocellular carcinoma, patients with portal vein thrombosis, patients with severe co morbid illness, use of vasoactive drugs in previous two weeks, patients with small varices which could not be banded, presence of isolated gastric varices.

During this period, 69 cirrhotic patients attended the department, out of which 29 were excluded due to various exclusion criteria, 4 patients had encephalopathy, 5 patients had spontaneous bacterial peritonitis, 6 patients had active bleeding, 4 patients had portal vein thrombosis, 1 patient had hepatocellular carcinoma, 5 patients had small varices, 1 patient had isolated gastric varices and was subjected to glue therapy, 4 patients had severe co morbid illness, of these two had chronic renal failure, 1 patient had hepatorenal syndrome, 1 patient had severe cardiopulmonary 
disease). Finally, 40 cirrhotic patients formed the study group.

At endoscopy, varices were graded as medium and large ${ }^{(20)}$. Small varices were defined as straight veins; collapsible with air insufflations. The severity of liver dysfunction was evaluated according to "Child-Turcotte-Pugh Scoring" (CTP) system ${ }^{(21)}$. At the time of study, all patients were clinically stable. The study protocol was approved by the ethical committee of the institution. All the patients gave written informed consent to participate after a complete explanation of the purpose of the study. No patient was on any vasoactive drugs at the time of study.

\section{Hemodynamic study}

Overnight -fasting patients were subjected to hepatic venous catheterization as described by Groszmann et al (10) through the right femoral vein route under local anesthesia with a $7 F$ Swan Ganz Catheter (Arrow Balloon Wedge Pressure Catheter) by using Seldinger technique in supine position. The catheter was placed into right hepatic vein under fluoroscopic guidance. Free hepatic venous pressure (FHVP) was recorded approximately 1-2 cms away from inferior vena cava in the right hepatic vein and balloon was advanced and then inflated to wedge the catheter. Subsequently, wedged hepatic venous pressure (WHVP) was recorded. After recording the WHVP, wedging was confirmed by the absence of reflux of contrast, 1-2ml injected through the catheter. FHVP was recorded on monitor (AXIOM- ARTIS Cine Angiography System Siemens). Portal pressures were measured as HVPG, the difference between WHVP and FHVP. All pressures were recorded in triplicate and final pressure was taken as mean of these 3 recordings. During the procedure, heart rate, blood pressure, pulse oximetry and ECG were continuously monitored. After pressure recording was complete, catheter was removed and local pressure applied for 10 minutes. Antiseptic dressing and pressure packing was applied which was removed after 24 hours. Post procedure, right leg was kept immobile for 24 hours. All patients were given oral Ofloxacin for 5 days following the procedure. All patients received tablet of pantaprazole $40 \mathrm{mg}$, once daily and non-selective beta blocker (NSBBs) until variceal obliteration was achieved.

\section{Complication}

one patient after HVPG measurement developed hematoma at local site which resolved within 48 hours, 2 patients had local pain which responded to analgesics.

\section{Endoscopic variceal ligation (EVL) sessions and follow up of patients}

Following measurement of baseline HVPG, all patients, were subjected to EVL. Same types of bands were used for variceal ligation in all patients (Vu-Max bands). Four to eight bands were applied at each sitting; depending upon number and size of varices. Initially, 2 endoscopic treatments were given at 10 day intervals to cause significant reduction in variceal size, and then further treatments were given at 3-week interval until variceal eradication. If extensive ulceration was found on subsequent endoscopy, treatment was postponed for 2 weeks and if minor ulceration was found, bands were placed avoiding site of ulceration as already described ${ }^{(22)}$. Varices were considered eradicated when they had either disappeared or were seen as residual straight small veins which collapsed on air sufflation. The endoscopist was totally unaware of the HVPG of the patients at time of doing EVL.

\section{Study protocol}

In all patients, we assessed success or failure of eradication of varices, number of EVL sessions required for variceal eradication.

\section{End point}

Complete variceal eradication

\section{Variceal eradication}

Complete disappearance of varices or residual small straight veins, collapsible with air insufflation. 


\section{Statistical method used}

Numerical data were expressed as mean \pm SD and categorical variables in terms of frequency and percentages. The standard statistical tests like Analysis of variance (ANOVA) technique, Student's independent t- test were used for continuous variables. Pearson's correlation coefficient and Partial linear regression analysis were used to see the association between the variables. Post hoc analysis was also done to see the significant difference between the groups. ${ }^{(23)}$ All the results so obtained were discussed on $5 \%$ level of significance i.e. $p$ value less than 0.05 was considered as significant. Statistical analysis was done by using SPSS 20 software package.

\section{Results}

There were 27 male and 13 females with mean age of 51.05 \pm 9.99 years. HPVG had no significant association with etiology of cirrhosis or history of bleeding. HPVG was higher in patients with Child-Pugh Class B \& C compared to Class A, and those with ascites, bleeders or with larger varices (Table 1). Ten patients had HVPG $\leq 12$ mmHg, 11 patients had HVPG in the range of 13 $15 \mathrm{mmHg}, 10$ patients had HVPG of $16-18 \mathrm{mmHg}$ and 9 patients had HVPG > $18 \mathrm{mmHg}$. Lowest recorded level of HVPG was $10 \mathrm{mmHg}$ and highest was $22 \mathrm{mmHg}$. Mean number of EVL sessions required for variceal eradication was significantly more in patients with higher HVPG levels as compared to patients with relatively lower HVPG levels. Mean number of EVL sessions required for variceal eradication was 2.10, 2.64, 4.10, 5.33 in patients with $H V P G \leq 12$, 13-15, 16-18 and >18 mmHg, respectively. The increase in number of EVL sessions with increasing level of HVPG was found to be significant $\quad(\mathrm{p}-<0.001) \quad$ (Table 2). Variceal eradication was achieved in all 40 patients. Minimum number of EVL sessions required for eradication was one, while maximum number was six. Patients requiring more number of EVL sessions had significantly ( $p<0.001)$ higher mean HVPG levels as compared to patients requiring less number of EVL sessions (Table 3).Patients requiring 3 or less number of sessions had significantly lower mean HVPG levels of 12.82 2.01 compared to patients requiring more than 3 numbers of sessions of EVL18.64 $\pm 1.49(\mathrm{p}<0.001)$ (Table 4).

Post hoc analysis revealed that while comparing patients with HVPG $<12 \mathrm{~mm}$ of $\mathrm{Hg}$ with those having HVPG of $13-15 \mathrm{~mm}$ of $\mathrm{Hg}$, the $\mathrm{p}$ value comes out to be non significant $\mathrm{p}=0.358$.While comparing patients with HVPG $<12$ with those having HVPG 16-18, and those with $>18$ the $\mathrm{p}$ value is highly significant $(\mathrm{p}<0.001)$. (Table 5). A significant positive correlation was found between HVPG and number of EVL sessions required for eradication of varices with correlation coefficient of 0.844 ,regression coefficient of 0.344 and $p$ value of $\leq 0.001$ (Table 6)

Table 1: Relation of HVPG with etiology, ,variceal score, bleeding status, ascites and degree of liver dysfunction.

\begin{tabular}{|l|l|l|l|l|}
\hline Parameter & Value & No. of Cases & HVPG $(\mathrm{mmHg})$ & P value \\
\hline \multirow{5}{*}{ Etiology } & Post-viral & 21 & $15.14 \pm 3.13$ & \\
\cline { 2 - 4 } & Wilson's Disease & 2 & $15.05 \pm 4.94$ & \\
\cline { 2 - 4 } & Alcohol & 3 & $15.0 \pm 5.0$ & \multirow{2}{*}{0.94} \\
\cline { 2 - 4 } & NAFLD & 6 & $16.67 \pm 4.45$ & \\
\cline { 2 - 4 } & Auto-Immune & 3 & $14.60 \pm 2.64$ & \\
\cline { 2 - 4 } & Cryptogenic & 5 & $11.91 \pm 1.64$ & \multirow{3}{*}{$<0.001$} \\
\hline Variceal grade & Medium Sized & 11 & $16.59 \pm 3.01$ & \\
\cline { 2 - 4 } & Large Sized & 29 & & \\
& & & & \\
\end{tabular}




\begin{tabular}{|c|c|c|c|c|}
\hline \multirow{2}{*}{$\begin{array}{l}\text { History of variceal } \\
\text { bleeding }\end{array}$} & Present & 26 & $17.19 \pm 2.56$ & \multirow{2}{*}{$<0.001$} \\
\hline & Absent & 14 & $11.79 \pm 1.42$ & \\
\hline \multirow[t]{2}{*}{ Ascites } & Present & 25 & $16.68 \pm 1.75$ & \multirow{2}{*}{$<0.001$} \\
\hline & Absent & 15 & $11.80 \pm 1.73$ & \\
\hline \multirow[t]{3}{*}{ Child pugh Class } & $\mathrm{A}$ & 15 & $11.93 \pm 1.48$ & \multirow[b]{3}{*}{$<0.001$} \\
\hline & $\mathrm{B}$ & 13 & $15.62 \pm 2.06$ & \\
\hline & $\mathrm{C}$ & 12 & $19.17 \pm 1.46$ & \\
\hline
\end{tabular}

NAFLD Nonalcoholic fatty liver disease

Table 2: Mean EVL sessions required for variceal eradication. in relation to HVPG levels.

\begin{tabular}{|l|l|l|l|}
\hline HVPG $(\mathrm{mmHg})$ & Mean EVL sessions & Standard Deviation & $p$ - value \\
\hline$\leq 12$ & 2.10 & 0.738 & \\
\hline $13-15$ & 2.64 & 0.505 & $<0.001$ \\
\hline $16-18$ & 4.10 & 0.738 & \\
\hline$>18$ & 5.33 & 0.500 & \\
\hline
\end{tabular}

Table 3: Mean HVPG in relation to number of EVL sessions required for variceal eradication.

\begin{tabular}{|c|c|c|c|c|c|c|}
\hline $\begin{array}{c}\text { EVL } \\
\text { sessions }\end{array}$ & $\begin{array}{c}\text { number of } \\
\text { patients }\end{array}$ & $\begin{array}{c}\text { Mean HVPG } \\
(\mathrm{mmHg})\end{array}$ & $\begin{array}{c}\text { Standard. } \\
\text { Deviation }\end{array}$ & Minimum & Maximum & P value \\
\hline 1 & 2 & 10.50 & 0.707 & 10 & 11 & 14 \\
2 & 9 & 11.89 & 1.453 & 10 & 18 & $<0.001$ \\
3 & 12 & 13.92 & 1.881 & 11 & 18 & \\
5 & 5 & 17.20 & 0.447 & 17 & 22 & \\
6 & 9 & 19.00 & 1.414 & 17 & 19 & \\
\hline
\end{tabular}

Table 4: HVPG correlation with EVL sessions required for variceal eradication.

\begin{tabular}{|l|l|l|l|}
\hline EVL SESSIONS & HVPG mean \pm SD & Mean difference & P value \\
\hline$\leq 3$ & $12.82 \pm 2.01$ & & \\
& \multirow{2}{*}{5.82} & $5.84 \pm 1.49$ & $<0.001$ \\
\hline
\end{tabular}

Table 5: Post Hoc analysis- [dependent variable - EVL sessions required for variceal eradication]

\begin{tabular}{|l|l|}
\hline Pair wise comparison & P value \\
\hline$\leq 12$ vs $13-15$ & 0.358 \\
\hline$\leq 12$ vs $16-18$ & $<0.001^{*}$ \\
\hline$\leq 12$ vs $>18$ & $<0.001^{*}$ \\
\hline $13-15$ vs $16-18$ & $<0.001^{*}$ \\
\hline $16-18$ & $<0.001^{*}$ \\
\hline
\end{tabular}

$*=\mathrm{p}$-value significant 
Table 6: Correlation of HVPG with number of EVL sessions required for eradication of varices using Partial correlation method, controlling the variceal size.

\begin{tabular}{|l|l|l|l|l|}
\hline $\begin{array}{l}\text { Dependent } \\
\text { variable }\end{array}$ & $\begin{array}{l}\text { Independent } \\
\text { variable }\end{array}$ & $\begin{array}{l}\text { Regression } \\
\text { coefficient }\end{array}$ & Significance & $\begin{array}{l}\text { Correlation } \\
\text { coefficient }\end{array}$ \\
\hline $\begin{array}{l}\text { No. of EVL } \\
\text { sessions }\end{array}$ & HVPG & 0.344 & $<0.001$ & 0.844 \\
\hline
\end{tabular}

Linear regression line

Sessions $=-2.309+0.344($ HVPG $)+0.298$ (large-sized varices $)$

\section{Discussion}

The present study was conducted on 40 consecutive patients of cirrhosis of liver of various etiologies with medium to large varices. In all patients baseline HPVG was measured and were subjected to variceal ligation until variceal eradication. Our primary aim was to study the influence of HPVG on variceal eradication. Twenty six patients received secondary prophylaxis and 14 patients had primary prophylaxis.

We found a relationship of higher variceal size with HVPG as reported by other authors ${ }^{(6,7,14)}$. Yet, some other authors have not found similar association ${ }^{(24,25)}$. In our study, we used EVL as means of variceal eradication as EVL has been shown to be significantly better in controlling bleeding compared to sclerotherapy ${ }^{(26)}$.

In our study we found that there exists strong positive correlation $(\gamma=0.844)$ between the number of EVL sessions and HPVG after controlling the independent effects of variceal size, that is as HPVG increases, the number of EVL sessions also increases. Regression coefficient shows that if there is a unit change in HPVG, there is significant $(<0.001)$ corresponding change in the number of EVL sessions. Post-hoc analysis on pair wise comparison shows that as HPVG rises, there is significant increase $(\mathrm{P}<0.001)$ in the number of EVL sessions required for eradication of varices .At present there is no literature available to support our findings.

It has been shown that HPVG is an important predictor of bleeding ${ }^{(27,28)}$. In our study we found significant association of HVPG level with history of bleeding, other authors have also had similar findings ${ }^{(6,14)}$. Merkel Carlo et al ${ }^{(29)}$ showed that HVPG was an important predictor of bleeding with a mean value of $21.7 \mathrm{mmHg}$ in those who bled during follow-up and $19.8 \mathrm{mmHg}$ in those who did not. We found no co-relation between HPVG and etiology of liver disease as has been reported by others ${ }^{(7,14)}$. We had 5 patients of cirrhosis who had small varices and were excluded from the study. These patients were put on NSBBs and are under follow up of endoscopic protocol yearly as defined ${ }^{(30)}$.

The current guidelines suggest two treatment strategies, NSBBs or EVL for primary prophylaxis of medium and large varices ${ }^{(20)}$. Only one RCT showed decrease in actuarial probability of first bleed in combination of EVL and propranolol group ${ }^{(31)}$.Since most of our patients were from remote far flung areas with no means of specialized treatment at periphery level, variceal ligation was performed every 2 weeks combined with NSBB.

\section{Limitations}

The number of patients studied is small. This kind of study needs to be done on a larger scale with greater number of patients. Post variceal eradication follow up of patients is needed to assess HVPG influence on recurrence of varices which is common post EVL.

\section{Conclusion}

HVPG is a safe procedure for assessment of portal hypertension. There is a good correlation between HVPG and large varices, bleeding status, and ascites. A higher HVPG reflects more severe liver disease. The etiology of liver disease did not influence the portal pressure. In correlation with 
esophageal varices, HVPG has a significant influence on response to EVL, in terms of number of sessions required for variceal eradication. Patients with high HVPG require more number of EVL sessions compared to patients with lower HVPG.

\section{References}

1. Boyer TD, Triger DR, Horisawa $M$, Redeker AG, Reynolds TB. Direct transhepatic measurement of portal vein pressure using a thin needle. Comparison with wedged hepatic vein pressure. Gastroenterology 1977: 72:584 -589.

2. Lin HC, Tsai YT, Lee FY, Chang TT, Wang SS, Lay CS, Lee SD, Lo KJ. Comparison between portal vein pressure and wedged hepatic vein pressure in hepatitis B-related cirrhosis. J Hepatol 1989:9:326-330

3. Perello A, Escorell A, Bru C, Gilabert R, Moitinho E, Garcia-Pagan JC, Bosh J. Wedged hepatic venous pressure adequately reflects portal pressure in hepatitis C virus-related cirrhosis. Hepatology 1999:30:1393-1397

4. Groszmann RJ, Bosch J, Grace ND, Conn HO, Garcia-Tsao G, Navasa M, Alberts J, Rodes J, Fischer R, Bermann $\mathrm{M}$, Hemodynamic events in a prospective randomized trial of propranolol versus placebo in the prevention of a first variceal hemorrhage. Gastroenterology 1990:99:1401-140.

5. Viallet A, Marleau D, Huet PM, Martin F, Farley A, Villeneuve JP, Lavoi P. Hemodynamic evaluation of patients with intrahepatic portal hypertension. Relationship between bleeding varices and the porto- hepatic gradient. Gastroenterology 1975:69:1297-1300.

6. Lebrec D, De Fleury P, Rueff B, Nahum $\mathrm{H}$, Benhamou JP. Portal hypertension, size of esophageal varices, and risk of gastrointestinal bleeding in alcoholic cirrhosis. Gastroenterology 1980: 79:1139 -1144 .

7. Wadhawan M, Dubey S, Sharma BC, Sarin SK. Hepatic venous pressure gradient in cirrhosis: correlation with the size of varices, bleeding ascites and Child's status. Dig Dis Sci 2006: 51:22642269

8. Suk KT, Kim CH,Park SH, Sung HT, Choi YJ, Han KH, Hong SH, Kim DY, Yoon JH, Kim YS, Baik GH, Kim JB, Kim DJ. Comparison of Hepatic venous pressure gradient and two models of end stage liver disease for predicting the survival in patients with decompensated liver cirrohosis. J Clin Gastroenterol 2012: 46:880-886

9. Ripoll C, Bañares R, Rincon D, Catalina MV, Lo Iacono O, Salcedo M, Clemente G, Nunez, Matilla A, Molinero LM. Influence of hepatic venous pressure gradient on the prediction of survival of patients with cirrhosis in the MELD Era. Hepatology 2005:42:793-801

10. Groszmann RJ, Garcia-Tsao G, Bosch J, Grace ND, Burroughs AK, Planas R, Escorsell A, Garcia-Pagan JC, Patch D, Matloff DS, Gao H, Makuch R. for the Portal Hypertension Collaborative Group. Beta blockers to prevent gastro esophageal varices in patients with cirrhosis. $\mathrm{N}$ Engl J Med 2005 : 353:2254-2261

11. Kim MY. Pathophysiology and diagnosis of portal hypertension. Korean $\mathrm{J}$ Med 2008: 75:1-5.

12. Merkel C, Bolognesi M, Bellon S, Zuin R, Noventa F, Finucci G, Sacerdoti D, Angeli P, Gatta A. Prognostic usefulness of hepatic vein catheterization in patients with cirrhosis and esophageal varices. Gastroenterology 1992:102:973-979

13. Gulzar GM , ZargarSA ,Sheikh J, AlaieMS, Javid G, Suri P K, Shah NA, Bilal-Ul-Rehman, Hakeem MS, Shoukat A, Dar GA. Correlation of 
hepatic venous pressure gradient with variceal bleeding, size of esophageal varices, etiology, ascites and degree of liver dysfunction in cirrhosis of liver. Indian J Gastroenterol 2009(MarchApril):28 (2):59-61.

14. Silkauskaite V, Pranculis A, Mitraite D, Jonaitis L, Petrenkiene V, KupcinskasL Hepatic venous pressure gradient measurement in patients with liver cirrhosis: a correlation with disease severity and variceal bleeding. Medicina (Kaunas) 2009: 45(1):8-13.

15. Burroughs AK, Jenkins WJ, Sherlock S, Dunk A, Walt RP, Osuafor TO, Mackie S, Dick R Controlled trial of propranolol for the prevention of recurrent variceal hemorrhage in patients with cirrhosis. $\mathrm{N}$ Engl J Med 1983: 309:1539 -1542.

16. Villeneuve JP, Pomier-Layrargues G, Infante-Rivard C, Willems B, Huet PM, Marleau D, Viallet A A. Propranolol for the prevention of recurrent variceal hemorrhage: a controlled trial. Hepatology 1986: 6:1239-1243.

17. Groszmann RJ, Bosch J, Grace ND, Conn HO, Garcia-Tsao G, Navasa M , Alberts J, Rodes J, Fischer R, Bermann $\quad M$. Hemodynamic events in a prospective randomized trial of propranolol versus placebo in the prevention of a first variceal hemorrhage. Gastroenterology 1990: 99:1401-1407.

18. Feu F, Garcia-Pagan JC, Bosch J, Luca A, Teres J, Escorsell A .Relation between portal pressure response to pharmacotherapy and risk of recurrent variceal haemorrhage in patients with cirrhosis. Lancet 1995: 346:1056 -1059

19. Suk KT. Hepatic venous pressure gradient: clinical use in chronic liver disease Clin Mol Hepatol 2014:20(1):6-14

20. DeFranchisR.Revising consensus in portal hypertension: report of Baveno $\mathrm{V}$ consensus workshop on methodology of diagnosis and therapy in portal hypertension.J Heptol 2010: 53:762-768.

21. Pugh RNH,Murray-Lyon IM,DawsonJL, PietroniMC,WilliamsR.Transection of the oesophagus for bleeding esophageal varices.Br J Surg 1973:60:646-649

22 Zargar SA,Javid G,Khan BA,Yatto GN, Shah AH, Gulzar GM, Sing J,Rehman B,Din Z.Endoscopic ligation compared with seclerotherapy for bleeding esophageal varices in children with extrahepatic portal vein obstruction. Hypertension. Hepatology 2002: 36:666-672.

23 Keppel G\&Wickens, T.D. Design and analysis: A researchers handbook $\left(4^{\text {th }}\right.$ Edition) (2004). Upper Saddle River, NJ: Pearson. Prentice Hall.

24 Patch D, Armonis A, Sabin C, K Christopoulou, L Greenslade, A McCormick, R Dick, A K Burroughs. Single portal pressure measurement predicts survival in cirrhotic patients with recent bleeding. Gut 1999:44:264-9.

25 Pemier-Layrargues G, Kusielewitcz D, Willems B, Villeneuve JP, Marleau D, Cote J, Huet PM. Presinusoidal portal hypertension in non-alcoholic cirrhosis. Hepatology 1985:5:415-8.

26 Triantos CK,Goulis J,Patch D, Papatheodoridis GV,Leandro G, Samonakis D,Chologitas E,Bourroughs AK .An evaluation of emergency sclerotherapy of varices in a randomized trail looking for the needle in the eye. Endoscopy 2006:38:797-807 30

27 D'Amico G, Garcia-Pagan JC, Luca A, BoschJ. Hepatic vein pressure gradient reduction and prevention of variceal bleeding in cirrhosis: a systematic review. Gastroenterology 2006:131:1611-1624.

28 Feu F, Garcia-Pagan JC, Bosch J, Luca A, Teres J, Escorsell A, Rodes J. Relation between portal pressure response to pharmacotherapy and risk of recurrent 
variceal haemorrhage in patients with cirrhosis. Lancet 1995:346:1056-1059.

29 Merkel C, Bolognesi M, Bellon S, Zuin R, Noventa F, Finucci G, et al. Prognostic usefulness of hepatic vein catheterization in patients with cirrhosis and esophageal varices. Gastroenterology 1992:102:973979.

30 Garcia-Tsao G, Sanyal AJ, Grace ND, Carey $\mathrm{W}$ Prevention and management of gastroesophageal varices and variceal hemorrhage in cirrohosis. Hepatology 2007:46:922-938.

31 Sarin SK, Wadhawan R, Agerwal SR, Tyagi P, Sharma BC.Endoscopic variceal ligation plus propanol versus endoscopic variceal ligation alone in primary prophylaxis of variceal bleeding Am J Gastroenterol 2005: 100:797-804. 